International Journal of Electrical Engineering and Technology (IJEET)

Volume 11, Issue 4, June 2020, pp. 392-403, Article ID: IJEET_11_04_044

Available online at https://iaeme.com/Home/issue/IJEET? Volume $=11 \&$ Issue $=4$

ISSN Print: 0976-6545 and ISSN Online: 0976-6553

DOI: https://doi.org/10.34218/IJEET.11.4.2020.044

(C) IAEME Publication

Scopus Indexed

\title{
COMPARATIVE ANALYSIS OF UPQC WITH VARIOUS HYSTERESIS CURRENT CONTROLLERS
}

\author{
A. Jeraldine Viji \\ Associate Professor, Department of Electrical and Electronics Engineering, \\ Mailam Engineering College, Villupuram District, Tamilnadu, India \\ Dr. S. Balasubramaniyan \\ Professor, Department of Electrical and Electronics Engineering, \\ Mailam Engineering College, Villupuram District, Tamilnadu, India
}

\begin{abstract}
This paper deals the comparative analysis of a three-phase three wire Unified Power Quality Conditioner (UPQC) with various hysteresis current controllers. The $U P Q C$ is one among the custom power devices which is a integration of series and shunt active power filters (APF) connected by a common link capacitor. The construction of shunt and series APF is by using a three phase three wire Voltage source Inverter (VSI). In series active filter, synchronous reference frame technique is used to extract fundamental voltage; whereas in shunt active filters, instantaneous reactive power theory(IRPT) is used to extract fundamental current. Switching pulses for both filters generated by hysteresis current controller (HCC), multilevel vector based hysteresis current controller (MVHCC) and adaptive hysteresis current controller(AHCC).The performance of the various HCC based control algorithm of shunt active filter with series active filter is evaluated in a three-phase distribution system connected with non-linear and unbalanced load conditions. Fuzzy logic control is used for dc capacitance balancing. The control technique is executed by the use of MATLAB / Simulink-based simulations environment.
\end{abstract}

Key words: Unified power quality conditioner, Synchronous reference frame technique, Instantaneous reactive power theory, multilevel vector based hysteresis current controller, Adaptive Hysteresis current controller, current and voltage harmonics.

Cite this Article: A. Jeraldine Viji and Dr. S. Balasubramaniyan, Comparative Analysis of UPQC with Various Hysteresis Current Controllers. International Journal of Electrical Engineering and Technology, 11(4), 2020, pp. 392-403.

https://iaeme.com/Home/issue/IJEET?Volume=11\&Issue $=4$ 


\section{INTRODUCTION}

The wide use of power electronics components in industries leads to power line disturbances in power system which propagates power quality problem like voltage sag swell and harmonics. This harmonics degrades the quality of power at consumer end. In past few decades, many papers had been addressed these problems and proposed the compensating techniques for eliminating this problem [1],[2]. The harmonics makes many undesirable effects such as increased heating losses in electrical machines and transformers, poor power factor, malfunction of sensitive equipments, torque pulsation of motors[3]. Power quality problems are eliminated by custom power devices(CPD).The most promising CPD is UPQC, which is a combination of two VSI connected in back to back manner, shares the common Dc bus [4].The function of series VSI is to compensate voltage quality problems and the shunt VSI mitigate the current related problems. Both series and shunt active filters works simultaneously so as to voltage delivered to the load regulated with low harmonic distortion [5].Controllers are the heart of UPQC, many researches proposed different control technique for generating reference voltage and current, gate pulse generation using PWM controllers and capacitance balancing[6-9].In this paper reference voltage generation needed for series active filter is synchronous reference frame(SRF) technique, similarly the reference current is generated by instantaneous reactive power theory(IRPT).For gate pulse generation many techniques are proposed like space vector modulation[10], dead beat control[11], hysteresis control[12],sliding mode control, and triangular current control method. Among all above methods hysteresis controller is compact and easily implemented without complex algorithm. So in this paper conventional hysteresis band control (CHCC), adaptive hysteresis controller (AHCC),vector based multilevel hysteresis current control(VBMHCC) [13],[14] are used. Finally a comparison is made between various HCC based UPQC. Maintaining constant DC voltage across capacitor is necessary in UPQC design. The dc link capacitor voltage will be changed during reactive power compensation [15]. In this paper fuzzy logic controller is used for capacitance voltage balancing. The control methods are evaluated and tested under nonlinear and unbalanced load conditions using Matlab/Simulink software.

\section{MATERIAL AND METHODS}

The UPQC consists of two voltage source inverters Connected back to back with each other sharing a common dc link [14].It is connected before the load to make the source and load voltages free from any voltage and current distortions and reactive current drawn from source is compensated in such a way that it is pure sinusoidal wave and in phase with supply voltage.

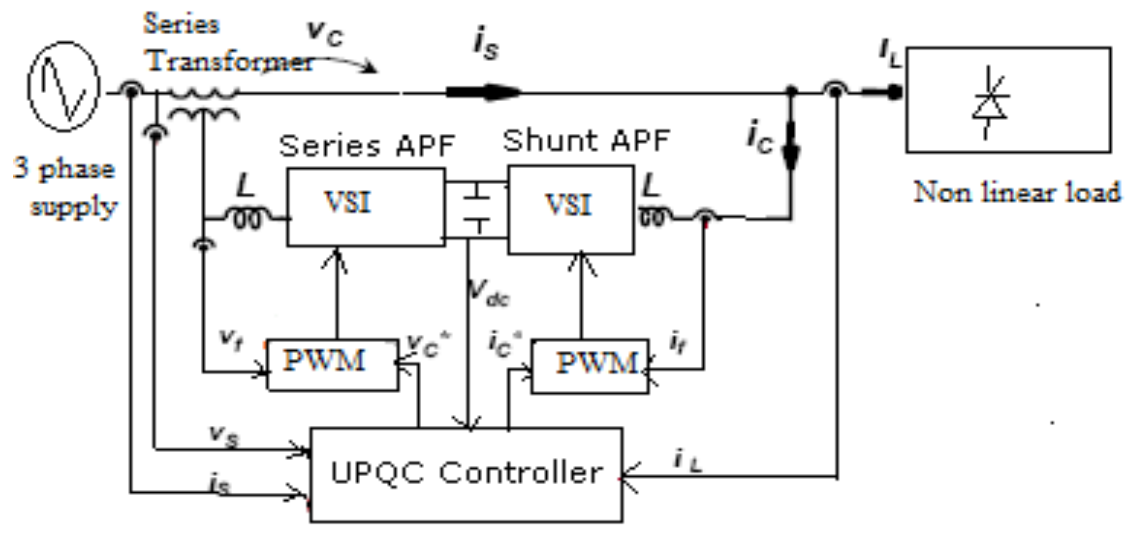

Figure 1 UPQC block Diagram 
The aim of the series APF is harmonic isolation between consumer load and Supply; it has the capability of compensating flicker/voltage imbalance as well as voltage regulation [14]. The function of shunt APF is used to absorb current harmonics, compensate reactive power, negative-sequence of source current, and regulate the dc link voltage between both APFs and power factor correction[15]. The General UPQC block diagram is shown in Figure 1.

\subsection{Reference Voltage Signal Generation of Series APF}

In series APF the inverter injects a voltage in series with the supply which feeds through a series transformer. The injected voltage usually the harmonics with small amount of sinusoidal component which results to compensate reactive power losses which maintains D.C voltage as constant [16]. The control algorithm calculates the required amount of reference value to be injected by the series transformers. The harmonic voltage is calculated by comparing the fundamental voltage component with the load side line voltages $[9,10]$. In equation (1), the three phase supply voltages $\mathrm{V}_{\mathrm{Sabc}}$ are transformed to d-q-0 co-ordinate.

$$
\left[\begin{array}{l}
V_{s 0} \\
V_{s d} \\
V_{s q}
\end{array}\right]=\frac{2}{3}\left[\begin{array}{ccc}
\frac{1}{2} & \frac{1}{2} & \frac{1}{2} \\
\sin (\omega t) & \sin \left(\omega t-2 \frac{\pi}{3}\right) & \sin \left(\omega t+2 \frac{\pi}{3}\right) \\
\cos (\omega t) & \cos \left(\omega t-2 \frac{\pi}{3}\right) & \cos \left(\omega t+2 \frac{\pi}{3}\right)
\end{array}\right]\left[\begin{array}{l}
V_{s a} \\
V_{s b} \\
V_{s c}
\end{array}\right]
$$

The d axis voltage $\left(\mathrm{V}_{\mathrm{Sd}}\right)$ contains both average and oscillating component $\bar{V}_{s d}, \widetilde{V}_{s d}$ shown in (2). The average voltage $\bar{V}_{s d}$ is found by using second order LPF (low pass filter).

$$
\mathrm{V}_{\mathrm{sd}}=\bar{V}_{s d}+\tilde{V}_{s d}
$$

The load side reference voltages $V^{*}$ Labc are calculated as given in equation (3). The switching signals are derived by comparing reference voltages $V^{*}{ }_{L a b c}$ and the load voltages $\mathrm{V}_{\text {Labc via PWM controller. }}$

$$
\left[\begin{array}{l}
V^{*}{ }_{L a} \\
V^{*}{ }_{L b} \\
V^{*}{ }_{L c}
\end{array}\right]=\frac{2}{3}\left[\begin{array}{ccc}
\sin (\omega t) & \cos (\omega t) & 1 \\
\sin \left(\omega t-2 \frac{\pi}{3}\right) & \cos \left(\omega t-2 \frac{\pi}{3}\right) & 1 \\
\sin \left(\omega t+2 \frac{\pi}{3}\right) & \cos \left(\omega t+2 \frac{\pi}{3}\right) & 1
\end{array}\right]\left[\begin{array}{c}
\bar{V}_{s d} \\
0 \\
0
\end{array}\right]
$$

The obtained three-phase load reference voltages are compared with load line voltages and errors are then processed by three different $\mathrm{HCCs}$ (vector base HCC, Conventional HCC, adaptive HCC), and gate pulse are generated. It is shown in Figure 2.

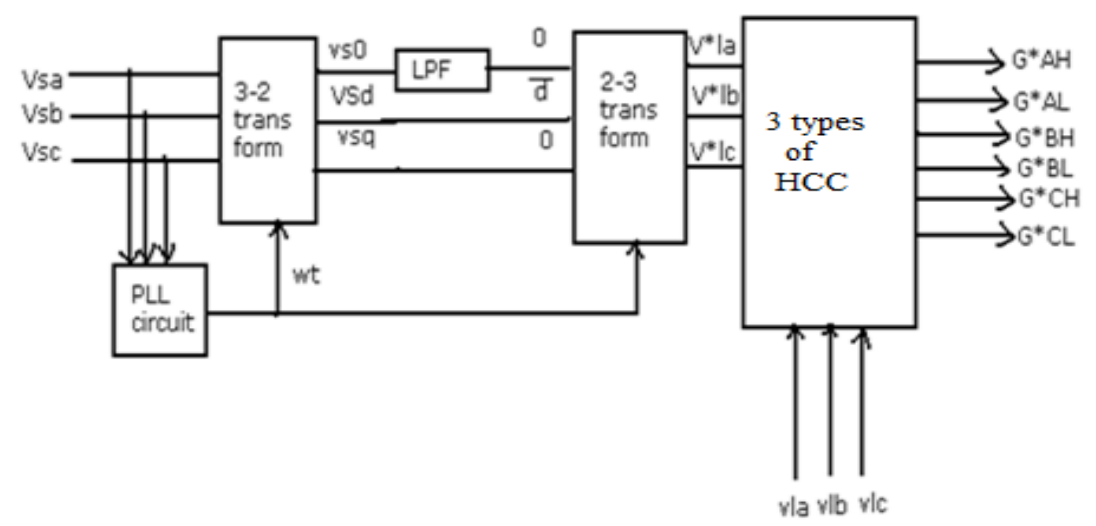

Figure 2 Reference voltage generation block Diagram 


\subsection{Reference Current Signal Generation of Shunt APF}

The function of shunt APF is to compensate the current harmonics, reactive power generated by the nonlinear load. Here thyristor bride rectifier is act as a non linear load. The instantaneous reactive power (p-q) theory is used to control of shunt APF in real time [16]. In this theory, the instantaneous three-phase currents and voltages are transformed to $\alpha-\beta-0$ coordinates as shown in equation (4) and (5).

$$
\begin{aligned}
& {\left[\begin{array}{l}
V_{0} \\
V_{\alpha} \\
V_{\beta}
\end{array}\right]=\sqrt{\frac{2}{3}}\left[\begin{array}{ccc}
\frac{1}{\sqrt{2}} & \frac{1}{\sqrt{2}} & \frac{1}{\sqrt{2}} \\
1 & -\frac{1}{2} & -\frac{1}{2} \\
0 & \frac{\sqrt{3}}{2} & -\frac{\sqrt{3}}{2}
\end{array}\right]\left[\begin{array}{l}
V_{s a} \\
V_{s b} \\
V_{s c}
\end{array}\right]} \\
& {\left[\begin{array}{l}
i_{0} \\
i_{\alpha} \\
i_{\beta}
\end{array}\right]=\sqrt{\frac{2}{3}}\left[\begin{array}{ccc}
\frac{1}{\sqrt{2}} & \frac{1}{\sqrt{2}} & \frac{1}{\sqrt{2}} \\
1 & -\frac{1}{2} & -\frac{1}{2} \\
0 & \frac{\sqrt{3}}{2} & -\frac{\sqrt{3}}{2}
\end{array}\right]\left[\begin{array}{l}
i_{s a} \\
i_{s b} \\
i_{s c}
\end{array}\right]}
\end{aligned}
$$

The instantaneous real and imaginary power components in the supply side are calculated by using source currents and phase-neutral voltages as given in (6). The instantaneous real and imaginary powers include both oscillating and average components as shown in equation (7). Average components of $\mathrm{p}$ and $\mathrm{q}$ consists of positive sequence components $\bar{p}$ and $\bar{q}$ of source current. The oscillating components $\bar{p}$ and $\widetilde{q}$ of $\mathrm{p}$ and $\mathrm{q}$ include harmonic and negative sequence components of source currents [4]. The harmonics in neutral current is reduced by calculating $\mathrm{P}_{0}$ by using average and oscillating components of imaginary power and oscillating component of the real power; as given in (8).In order to compensate the active power losses of the UPQC, active power is injected to the power system by the series of APF, which causes dc-link voltage reduction. In parallel APF, the active power is absorbed from the power system for regulating dc-link voltage. Due to absorption and injection of active power, the dc link voltage is not maintained constant.The signal $\mathrm{P}_{\text {loss }}$ forces the shunts active filter to drain from the power system to the total energy that is delivered to the load. That is why necessitate to maintain dc-link voltage of the UPQC as constant.. $i^{*}{ }_{s \alpha} i^{*}{ }_{s \beta}, i^{*}{ }_{s 0}$ are the reference currents of shunt APF in $\alpha-\beta-0$ co-ordinates. The three phase reference currents are generated by using $\alpha, \beta$ axis source current as shown in (9).

$$
\begin{gathered}
{\left[\begin{array}{l}
p_{q} \\
q
\end{array}\right]=\left[\begin{array}{cc}
V_{\alpha} & V_{\beta} \\
-V_{\beta} & V_{\alpha}
\end{array}\right]\left[\begin{array}{l}
i_{\alpha} \\
i_{\beta}
\end{array}\right]} \\
P_{0}=v_{0} I_{0} ; \mathrm{p}=\bar{p}+\tilde{p} \\
{\left[\begin{array}{l}
i^{*}{ }_{s \alpha} \\
i^{*}{ }_{s \beta}
\end{array}\right]=\frac{1}{V_{\alpha}^{2}+V_{\beta}^{2}}\left[\begin{array}{cc}
V_{\alpha} & -V_{\beta} \\
V_{\beta} & V_{\alpha}
\end{array}\right]\left[\begin{array}{c}
\bar{p}+p_{0}+\bar{p}_{\text {loss }} \\
0
\end{array}\right]} \\
{\left[\begin{array}{l}
i^{i^{*}}{ }^{*}{ }_{s b} \\
i^{*}{ }_{s c}
\end{array}\right]=\sqrt{\frac{2}{3}}\left[\begin{array}{ccc}
\frac{1}{\sqrt{2}} & 1 & 0 \\
\frac{1}{\sqrt{2}} & -\frac{1}{2} & \frac{\sqrt{3}}{2} \\
\frac{1}{\sqrt{2}} & -\frac{1}{2} & -\frac{\sqrt{3}}{2}
\end{array}\right]\left[\begin{array}{l}
i^{*}{ }_{s 0} \\
i^{*}{ }_{s \alpha} \\
i^{*}{ }_{s \beta}
\end{array}\right]}
\end{gathered}
$$

The reference currents are calculated in order to compensate neutral, harmonic and reactive currents in the load. These reference source current signals are then compared with sensed three-phase source currents and the errors are processed by three different HCCs(vector base HCC, Conventional HCC, adaptive HCC), and gate pulse are generated. It is shown in Figure 3. 


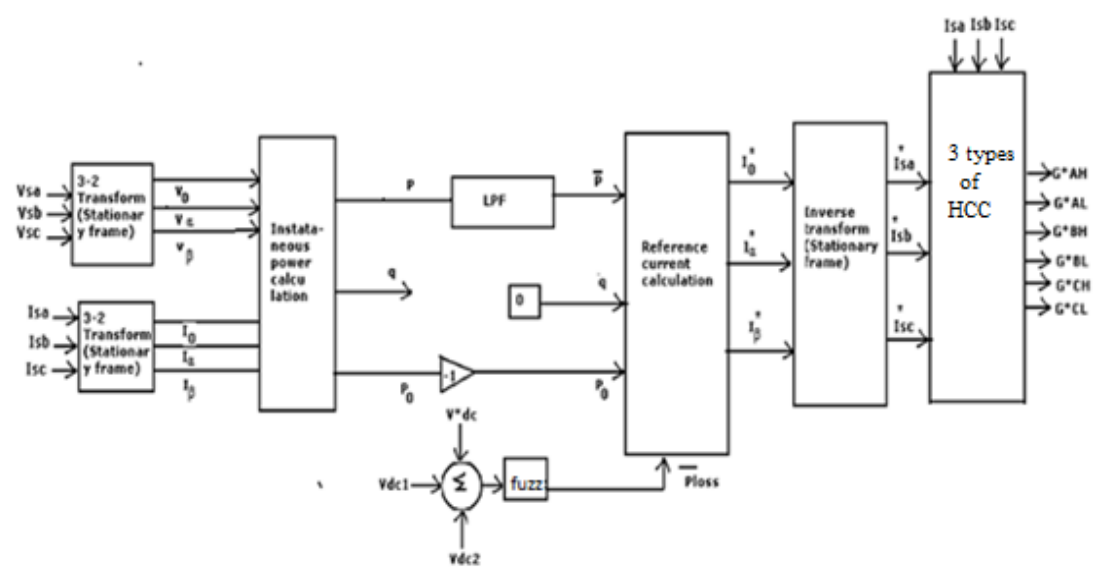

Figure 3 Reference current generation block Diagram

\section{CONTROL STRATEGY}

In this paper three different current control strategies are discussed such as vector based multilevel hysteresis current controller (VBMHCC), Conventional HCC and Adaptive Hysteresis current controller(AHCC).

\subsection{Vector Based Multilevel HCC}

When the actual inverter current or voltage crosses the tolerance region on one side, a new vector with opposite component on that side must be applied. This method gives a switching pattern constituted of six consecutive four-state optimal voltage vectors sets, which matches with six 60 degree sectors of a fundamental period [17]. At each instant digital outputs of the hysteresis comparators determines the discrete state of the inverter output voltage according to the table 1.The overall switching pattern is shown in Figure 4.The vector based hysteresis current controller is shown in Figure 5.The current error is always kept inside the square tolerance region [18]. The vector based hysteresis controller is used for both filters for producing switches pulses.

Table 1 inverter output voltage

\begin{tabular}{|c|c|c|c|}
\hline $\mathbf{D}_{\boldsymbol{\alpha}}$ & & & \\
\hline 0 & $\mathbf{0}$ & $\mathbf{1}$ & $\mathbf{2}$ \\
\hline 0 & $\mathrm{~V} 5$ & $\mathrm{~V} 4$ & $\mathrm{~V} 3$ \\
\hline 1 & $\mathrm{~V} 5$ & $\mathrm{~V} 0$ & $\mathrm{~V} 3$ \\
\hline 2 & $\mathrm{~V} 6$ & $\mathrm{~V} 0$ & $\mathrm{~V} 2$ \\
\hline 3 & $\mathrm{~V} 6$ & $\mathrm{~V} 1$ & $\mathrm{~V} 2$ \\
\hline
\end{tabular}

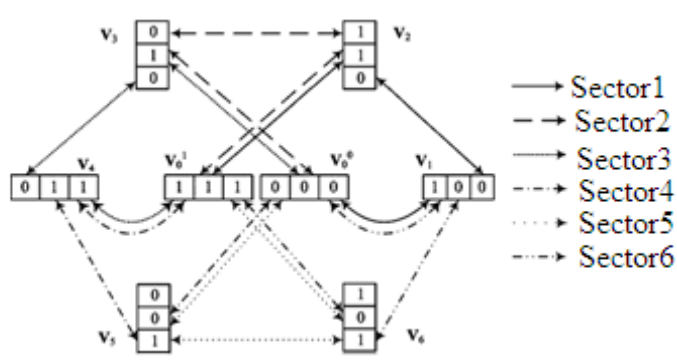

Figure 4 Over all switching pattern 


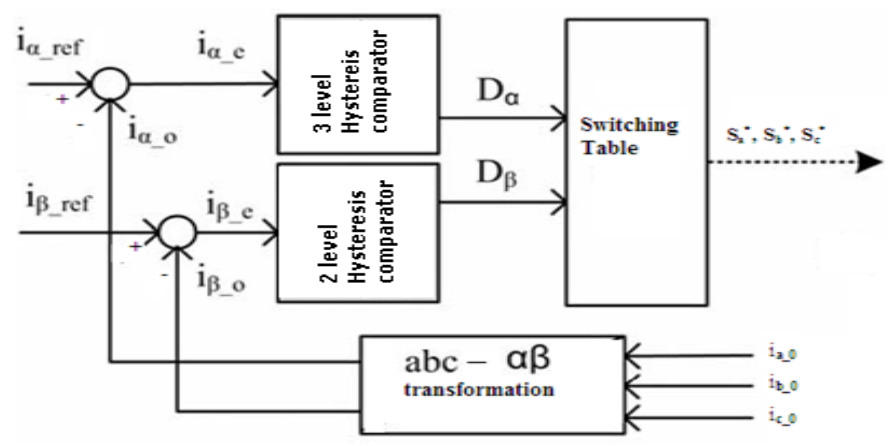

Figure 5 Vector based hysteresis current controller

\subsection{Conventional HCC}

This method is done by comparing the measured current from load side with reference current, error is generated. According to the error switching pulses are produced. In this method the input reference should always with the specified band width. The switching logic is expressed as follows

If $\mathrm{e}_{\mathrm{m}}>\mathrm{HB} \mathrm{T}_{1}$ is $\mathrm{On}, \mathrm{T}_{2}$ is $\mathrm{OFF}$.

$e_{m}<-H B T_{1}$ is OFF, $T_{2}$ is On. Where $m$ indicates $a, b$, cphases. wheree ${ }_{m}=i_{\text {ref }}-i_{\text {measured, }}$ HB represents the hysteresis band.

The performance of the HCC depends on the coupling inductance, dc voltage capacitance, hysteresis band. The conventional HCC diagram is shown in Figure 6.
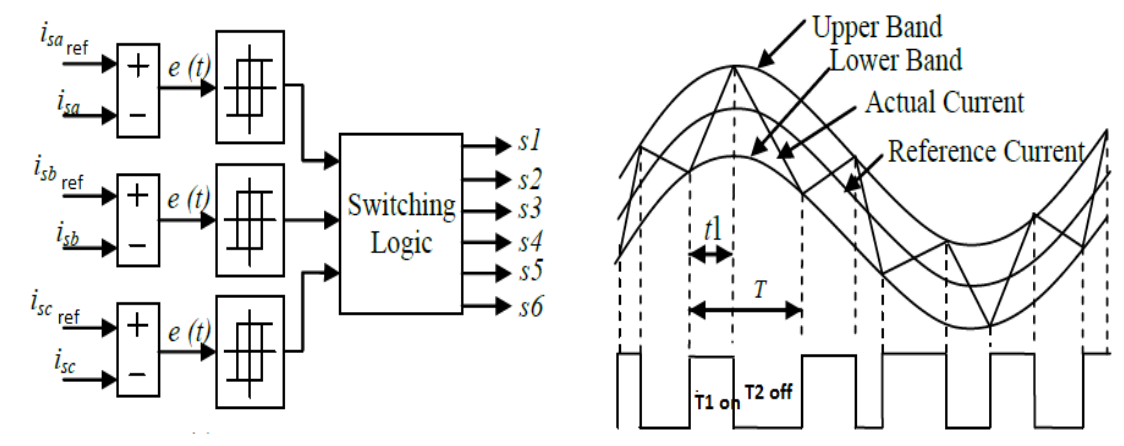

Figure 6 Conventional HCC

\subsection{Adaptive HCC}

When the current error $\mathrm{e}_{\mathrm{m}}$ exceeds the upper limit of the adaptive-hysteresis band, the lower switch is turned ON. If the error current or voltage crosses the lower limit of the adaptivehysteresis band, the upper switch is turned ON. Hence, the actual current is forced to track the reference current within the hysteresis-band [18]. The following equations can be written for the switching interval $\mathrm{t} 1$ and $\mathrm{t} 2$.

$$
\frac{d i_{s a}^{+}}{d t}=\frac{1}{L}\left(v_{d c}-v_{s}\right), \frac{d i_{s a}^{-}}{d t}=-\frac{1}{L}\left(v_{d c}-v_{s}\right)
$$

the following equations can be written in the hysteresis-band curvature with respective switching intervals

$$
\frac{d i_{s a}^{+}}{d t} t_{1}-\frac{d i_{s a}^{*}}{d t} t_{1}=2 H B, \frac{d i_{s a}^{-}}{d t} t_{2}-\frac{d i_{s a}^{*}}{d t} t_{2}=-2 H B, t_{1}+t_{2}=1 / f_{c}
$$


From the above equation HB is calculated as,

$$
H B=\frac{0.25 v_{d c}}{f_{c} L}\left[1-\frac{L^{2}}{v_{d c^{2}}}\left(\frac{v_{s}}{L}+m\right)^{2}\right]
$$

Where $\mathrm{L}$ is the coupling inductance, $v_{s}$ is the supply voltage, $f_{c}$ is the modulation frequency, $v_{d c}$ is the voltage across the capacitance, $m=\frac{d i_{a}^{*}}{d t}$ is the slope of reference current signals. The hysteresis band $H B$ can be modulated at different points of fundamental frequency to control the switching pulses of the inverter. The calculated hysteresis bandwidth $H B$ is applied to the switching operation of HCC to produce gate control-switching pulses to drive the inverter. The adaptive HCC diagram is shown in Figure 7.
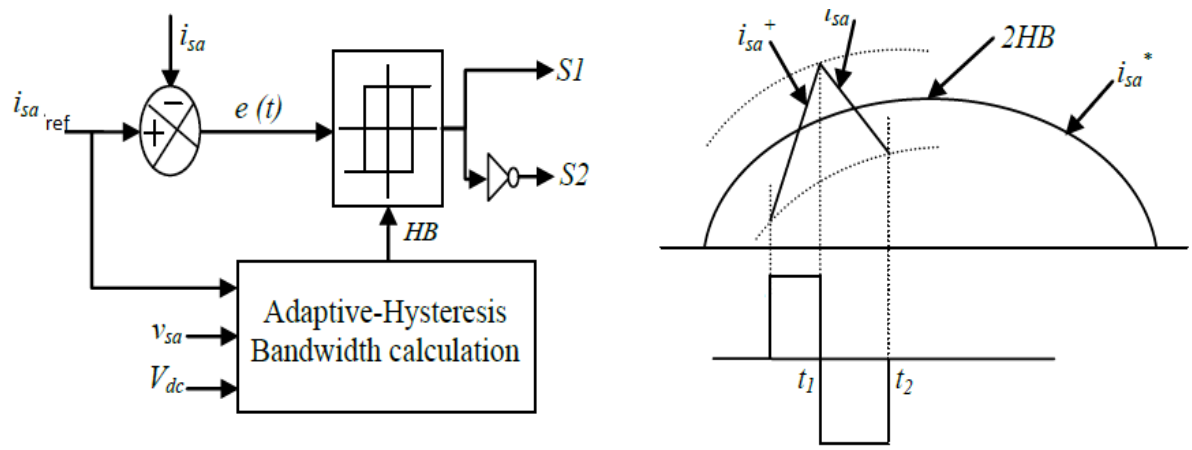

Figure 7 Adaptive HCC.

\section{CAPACITANCE VOLTAGE BALANCING}

The voltage across the capacitance is sensed and compared with reference value for capacitance balancing in order to minimize the energy loss. Then the error is passed to fuzzy controller for getting constant value. Fuzzy logic is characterized by seven fuzzy sets as a input and output variable and 49 rules are formed, triangular membership function is used for the simplicity, mamdani min type is used as a implication, de-fuzzification using by the height method shown in Figure 8. The table 2 shows the fuzzy base rule.

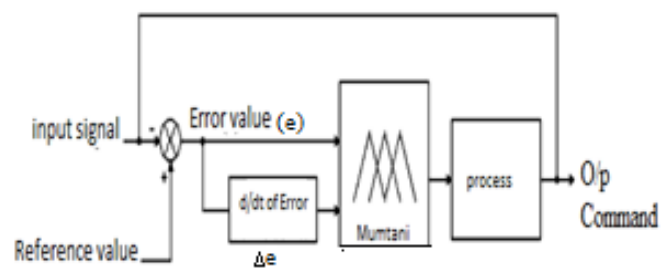

Figure 8 Fuzzy Logic Controller

Table 2 Fuzzy rule base

\begin{tabular}{|c|c|c|c|c|c|c|c|}
\cline { 2 - 8 } \multicolumn{1}{c|}{} & \multicolumn{7}{c|}{ change in error( $\mathbf{\Delta e})$} \\
\hline error(e) & NL & NM & N S & Z & PS & PM & PL \\
\hline NL & NL & NL & NL & NL & NM & NS & Z \\
\hline NM & NL & NL & NL & NM & NS & Z & PS \\
\hline NS & NL & NL & NM & NS & Z & PS & PM \\
\hline Z & NL & NM & NS & Z & PS & PM & PL \\
\hline PS & NM & NS & Z & PS & PM & PL & PL \\
\hline PM & NS & Z & PS & PM & PL & PL & PL \\
\hline PL & Z & PS & PM & PL & PL & PL & PL \\
\hline
\end{tabular}




\section{SIMULATION RESULTS}

In this study, different HCC based control algorithms for the UPQC are examined simulation software. This system compensates the current harmonics produced by a thyristor bridge rectifier and eliminates the voltage harmonics under unbalance load condition. This 3P4W UPQC system consists of two voltage controlled inverters (shunt and series APFs) sharing the same dc bus in split-capacitor topology. A ripple $R C$ filter is connected between output of series APF and the line. A $2100-\mu \mathrm{F}$ of dc capacitors having $700-\mathrm{V}$ dc is connected between two APFs in split capacitor topology. A three-phase and a single-phase thyristor bridge rectifier are used as nonlinear loads. The control algorithm for the UPQC is evaluated by Matlab / Simulink software. The system is investigated under unbalanced load conditions. The system parameters used are Line to line source voltage V rms is $380 \mathrm{~V}$; System frequency (f) is $50 \mathrm{~Hz}$; Source inductance is $\mathrm{L}_{\mathrm{s}}$ is $0.7 \mathrm{~m} \mathrm{H}$; Series side Filter impedance of $\mathrm{R}_{\mathrm{c} 1}, \mathrm{~L}_{\mathrm{c}}, \mathrm{C}_{\mathrm{c} 1}$ is $90 \Omega, 0.8 \mu \mathrm{H}, 50 \mu \mathrm{F}$; Shunt side Filter impedance of $\mathrm{R}_{\mathrm{c} 2}, \mathrm{~L}_{\mathrm{c} 2}, \mathrm{C}_{\mathrm{c} 2}$ is $10 \Omega, 2.5 \mathrm{mH}, 8 \mu \mathrm{F}$; three phase thyristor rectifier $\mathrm{R}_{\mathrm{L}}, \mathrm{L}_{\mathrm{L}}$ load: $20 \Omega ; 10 \mathrm{~m}$ H respectively; Unbalanced three phase load resistances are $R_{1}=10 \Omega, R_{2}=50 \Omega, R_{3}=80 \Omega$ and Load inductance $L_{L}$ is $80 \mathrm{~m} \mathrm{H}$; DC side capacitance is $2100 \mu \mathrm{F}$; Reference voltage $\left(\mathrm{V}_{\mathrm{DC}}\right.$, ref $)$ is $700 \mathrm{~V}$,switching frequency of series and shunt inverter is approximately $10 \mathrm{KHz}$.

\subsection{UPQC OFF Condition}

The Figure 9(a) indicates source voltage before compensation. The thyristor rectifier load current or source current before compensation is shown in Figure 9 (b). The Neutral current is shown in Figure 9 (c). The THD of the Source Voltage and Current before compensation is $27.6 \%$ and $28.5 \%$.

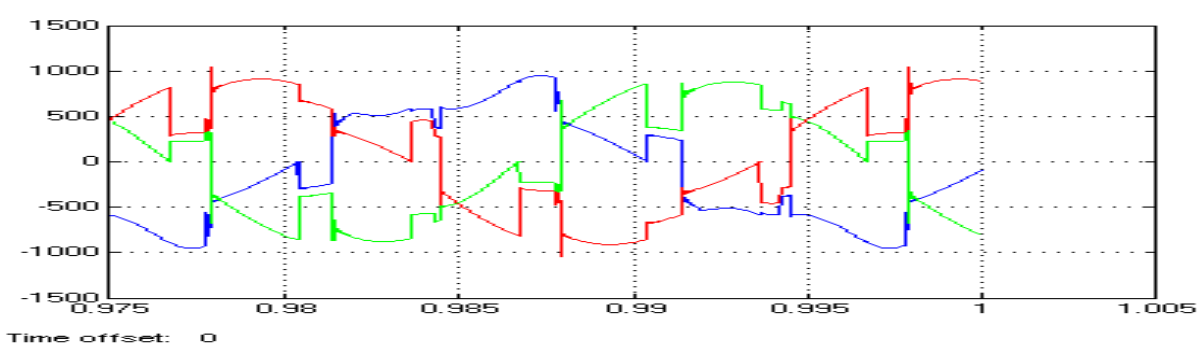

Figure 9 (a) Source voltage (UPQC OFF)

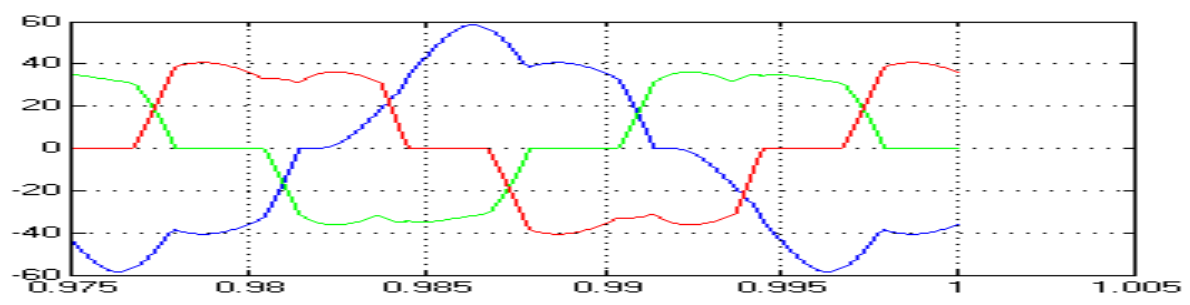

Figure 9(b) Source current (UPQC OFF)

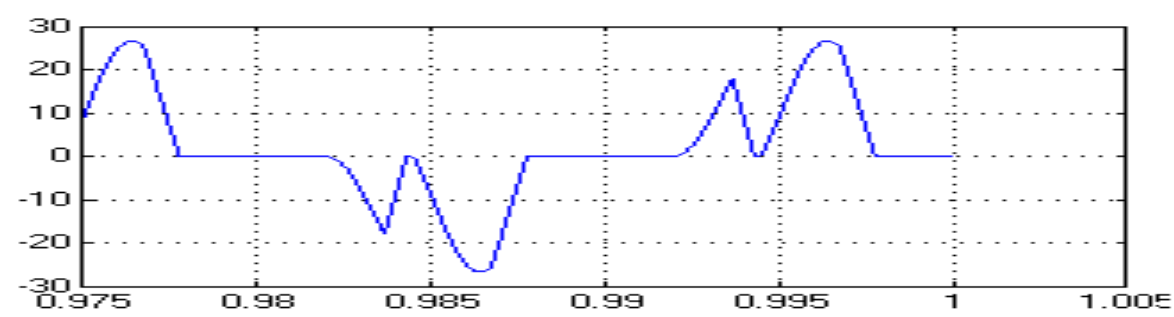

Figure 9(c) Neutral current (UPQC OFF) 


\subsection{UPQC ON Condition}

The source voltage after compensation of different HCC is presented (VBMHCC, Conventional HCC, AHCC) in Figure 10 (a), this figure indicates the source voltage is sinusoidal. The source current after compensation of different HCC is presented (VBMHCC, Conventional HCC, AHCC) is presented in Figure 10 (b) this indicates the input supply current is sinusoidal. The APF is suppressing reactive/harmonic power and simultaneously improves power factor. The neutral current of UPQC(all HCC method) is presented in Figure 10 (c).The Fast Fourier Transform (FFT) is used to measure the order of harmonics in source voltage, source current. All this results shown in Figure10 (d )and 10(e)
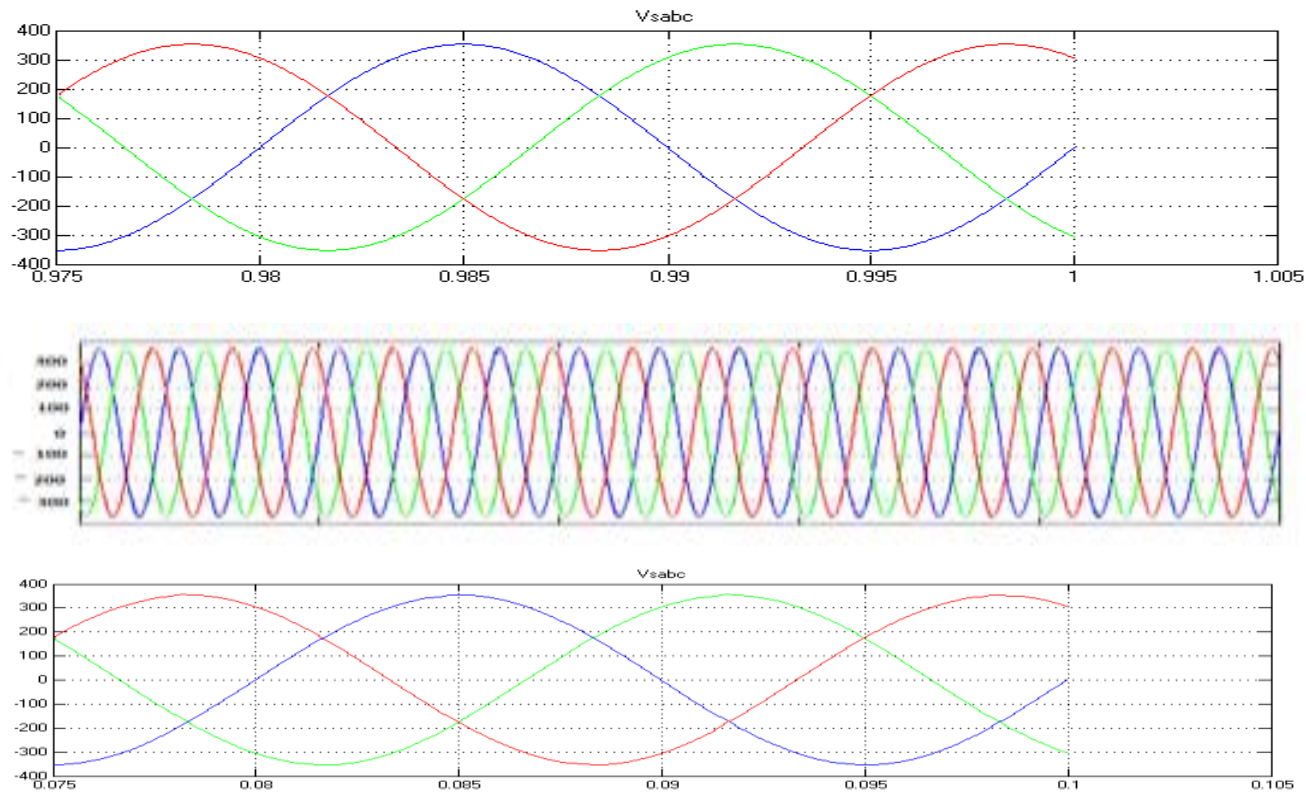

Figure 10 (a) Source voltage (UPQC ON)(VBM HCC, Conventional HCC, Adaptive HCC)
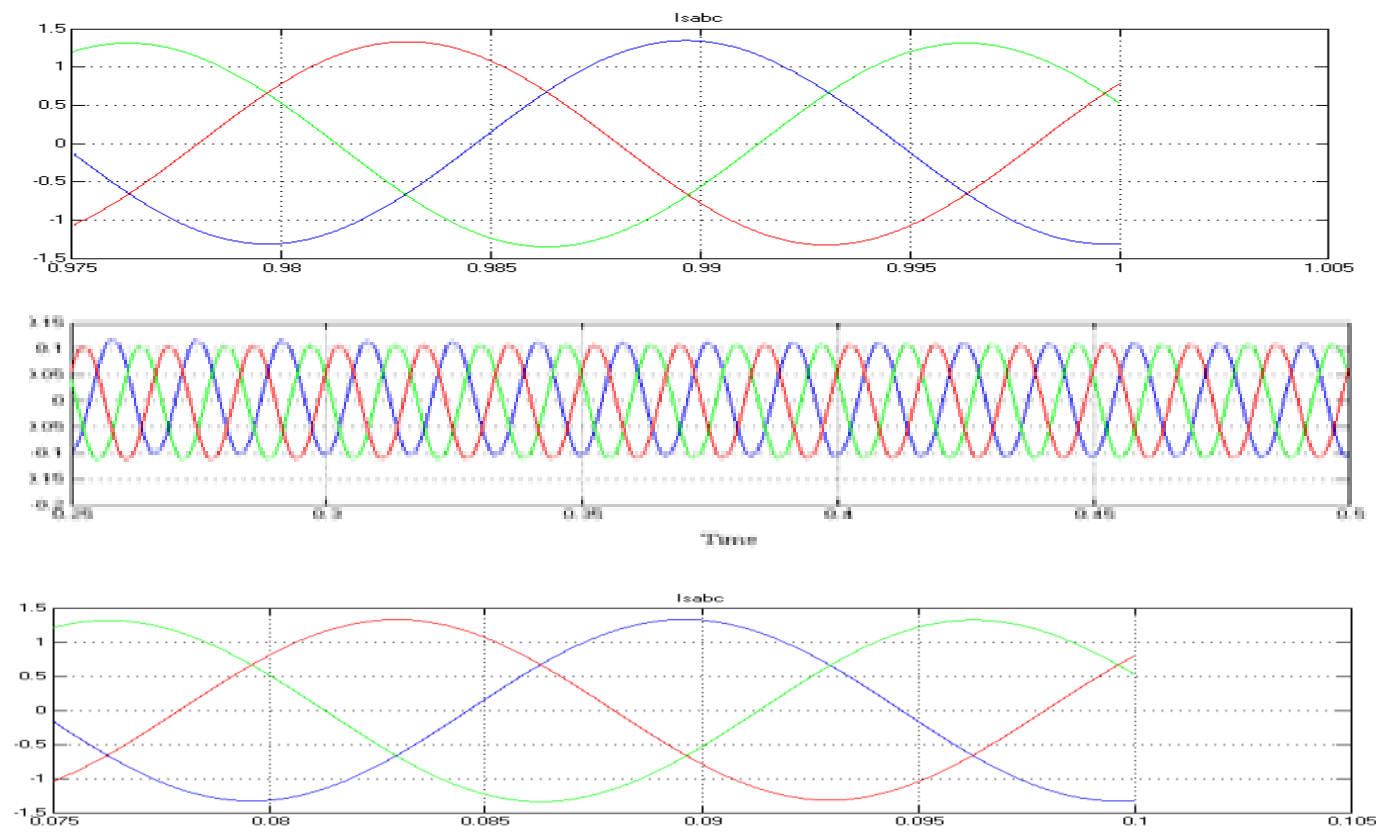

Figure 10 (b) Source Current (UPQC ON)(VBM HCC, Conventional HCC, Adaptive HCC) 

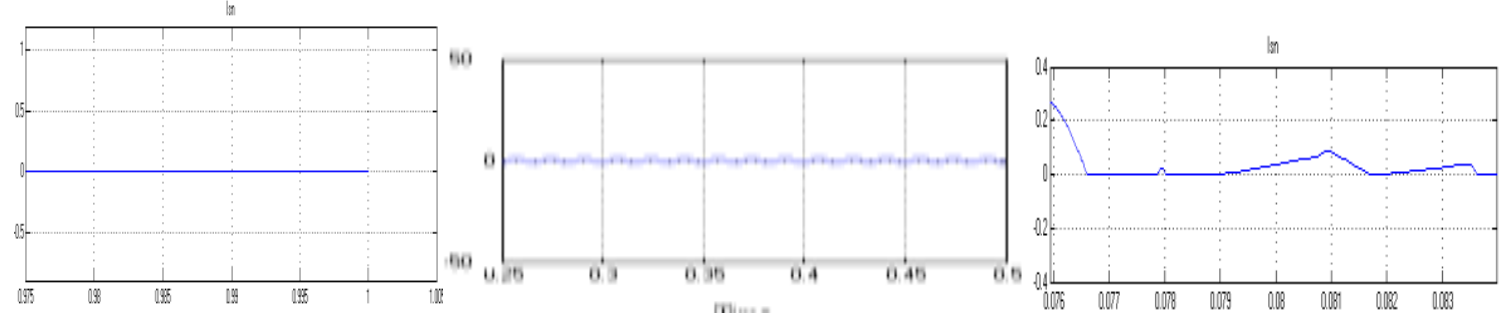

Figure 10 (c) Neutral current (VBM HCC, Conventional HCC, Adaptive HCC)
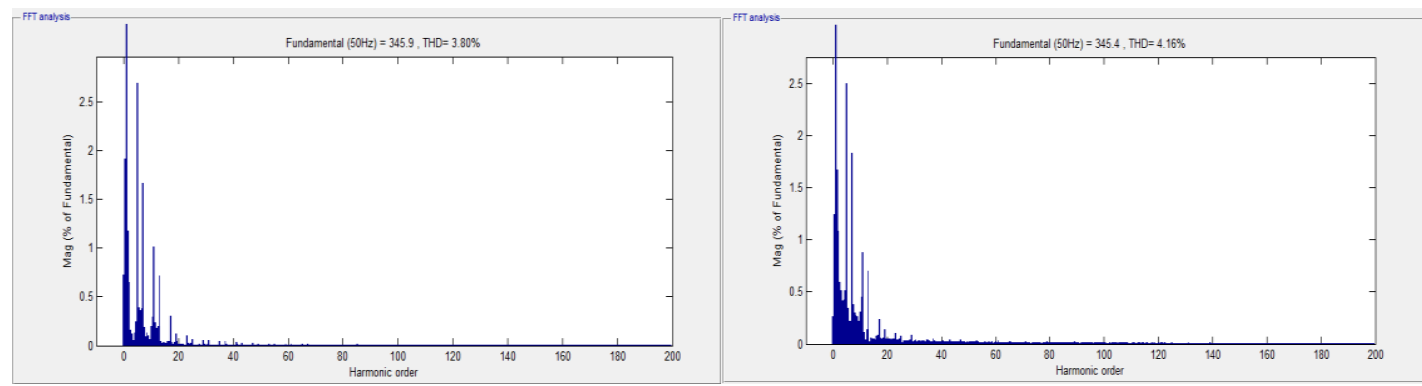

VBM HCC

Conventional HCC

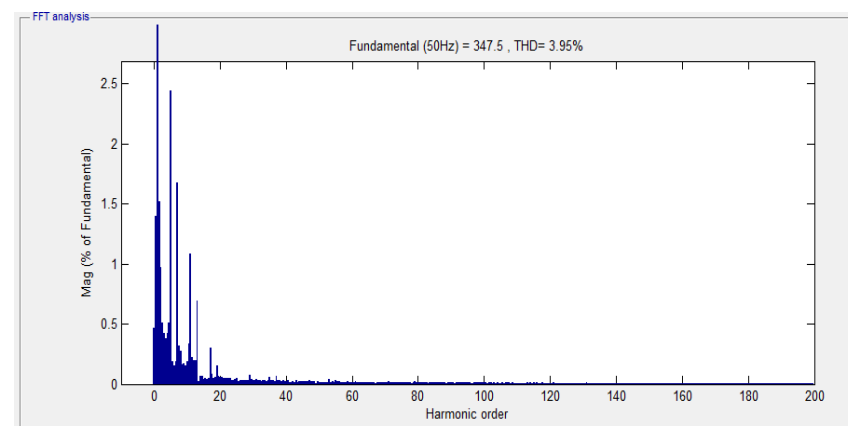

Adaptive HCC

Figure 10 (d) THD of source current

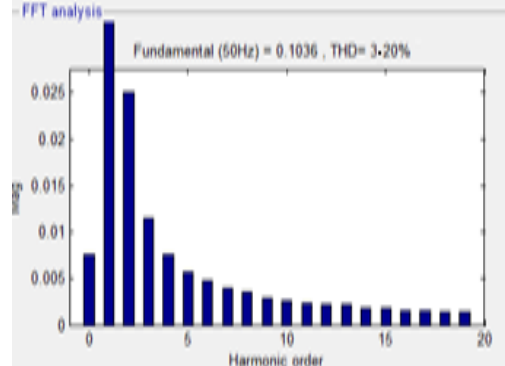

Harmonic order

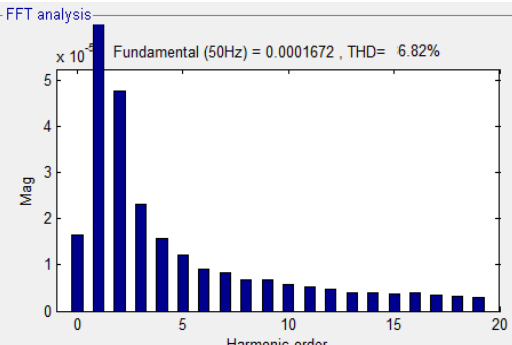

Harmonic order

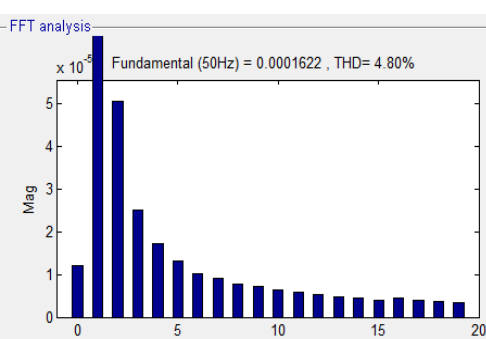

Harmonic order

Figure 10 (e) THD of source voltage(VBM HCC, Conventional HCC, Adaptive HCC)

\section{CONCLUSION}

This paper explains the UPQC compensation, that is reactive power along with voltage and current harmonics under unbalanced load conditions. In series and shunt Active filters, the reference voltages and currents are generated by SRF and IRPT method. In both filters conventional HCC, AHCC, VBMHCC based current controllers are used for gate pulse generation. The proposed UPQC is validated using extensive Matlab simulation. The important performance parameters are presented graphically and THD of source current is 
found to be $3.80 \%, 4.16 \%, 3.96 \%$ under unbalanced load condition of UPQC with Vector based HCC current controller, conventional HCC based current controller, adaptive HCC and From simulation results, it is evident that the value of THD is low in Vector based HCC method when compared with conventional HCC, adaptive based UPQC. In both methods, the measured total harmonic distortion of the source current and voltage are low in compliance with IEEE 519 standards.

\section{REFERENCES}

[1] A.S. N. Anjali Devi, G. Madhavi, (2016) "Unified Power Quality Conditioner In Distribution System For Enhancing Power Quality", International Journal of Electrical Engineering \& Technology (IJEET) Volume 7, Issue 6, Nov-Dec, pp.55-63

[2] Emanuel Alexander E Orr John A Cyganski David Gulachenski Edward M, (1993) ".A survey of harmonic voltages and currents at the customer's bus". IEEE Transactions on Power Delivery;8(1):pp.411-21.

[3] A.Jeraldine Viji, T.Aruldoss Albert Victiore, (2014) "Enhanced PLL based SRF control method for UPQC with fault protection under unbalanced load condition". International Journal of Electrical power and Energy System, issue 6, Vol:58 pp.No:319-328.

[4] R.A Walling, R.Saint, Dugan, R.C.J Burke and L.A.Kojovic, (2008) "Summary of Distributed Resources Impact on Power Delivery Systems." IEEE Trans. Power Delivery 23(3):pp.1636-1644.

[5] W.M.Grady M.J.Samotyj A.H.Noyola. (1990) "Survey of Active Power Line Conditioning Methodologies." IEEE Trans on Power Delivery, 5(3):pp.1536-1542

[6] D. Graovac A. Katic A. Rufer, (2007) "Power Quality Problems Compensation with Universal Power Quality Conditioning System." IEEE Transaction on Power Delivery, 22(2):pp.968-976.

[7] H. Carneiro L. F. C. Monteiro J. L. Afonso, (2009) "Comparisons between Synchronizing Circuits to Control Algorithms for Single-Phase Active Converters," IEEE Annual Conference of Industrial Electronics, pp.3229-3234.

[8] P.H. Zope, A. Somkuwar, (2012) "Design and Simualtion of single-phase Z-source inverter for utility interface, International journal of Electrical Engineering and Technology. Vol.1,pp.127-143.

[9] Y. Tang, S. Xie, C. Zhang, (2011) "An Improved Z-Source Inverter, IEEE Transactions on Power Electronics", 26,pp. 3865-3868.

[10] V. Saravanan, R. Ramanujam, M. Arumugam, (2015) "Novel improved three level Zsource inverter," Australian Journal of Electrical and Electronics Engineering.Vol.12,pp.133-140

[11] Zeng J Yu C Qi Q, (2004) "A novel hysteresis current control for active power filter with constant frequency, "Electric power system research; 68:75-82.

[12] M.A Aredes, (1995) "Combined series and shunt active power filter. "IEEE proc- Power Tech Conf ; $18-22$.

[13] Y. Chen, X ZhaWang, (2000) "Unified power quality conditioner (UPQC): The theory, modeling and application. Power System Technology," Power Con Int. Conf proc-; 3:1329-1333.

[14] F.Z Peng, J.W McKeever, D.J Adams, (1998) "A power line conditioner using cascade multilevel inverters for distribution systems." IEEE Trans.Ind. Appl; 34(6): 1293-1298. 
Comparative Analysis of UPQC with Various Hysteresis Current Controllers

[15] G.M Lee D.C Lee J.K Seok, (2004) "Control of series active power filter compensating for source voltage unbalance and current harmonics". IEEE Transaction on Industrial Electronics. 51(1):pp.132- 139.

[16] Bose Bimal K, (1990) "An adaptive band current control technique of a voltage fed PWM inverter for machine drive system." IEEE Trans.Ind.Elec. 31(5):pp.402-408.

[17] Bellhaouchet N Rahmani, (2009)" Development of adaptive hysteresis band current control of PWM three phase AC chopper with constant switching frequency. "International journal of Elec. Power.Com.and Sys. 33(10):pp.583-598.

[18] Mansour Mohseni Syed M Islam, (2010) "A new vector based hysteresis current control scheme for three phase PWM voltage source Inverters." IEEE Trans.Power.Elec. 25(9):pp.2299-2309. 